\title{
How innovative climate leads to project success: the moderating role of gender and work culture
}

Role of gender and work culture

\author{
Department of Management Sciences, COMSATS University Islamabad, \\ Islamabad, Pakistan \\ Muhammad Kashif Imran \\ Department of Management Sciences, \\ Islamia University of Bahawalpur, Bahawalpur, Pakistan \\ Zafar-Uz-Zaman Anjum \\ Department of Management Sciences, \\ COMSATS University Islamabad, Islamabad, Pakistan, and \\ Umer Zahid \\ COMSATS University Islamabad, Islamabad, Pakistan
}

\begin{abstract}
Purpose - In modern times, innovation is considered as a vital component of sustainable competitive advantage. The purpose of this paper is to identify how innovation at the individual level [innovative work behavior (IWB)] and at the organizational level [innovative organizational climate (IOC)] affects the chances of success of a particular project. Additionally, the moderating effect of gender and work culture on the relation between innovative climate and behavior is tested in the study.

Design/methodology/approach - Survey technique was used to collect data from 425 employees working in project departments at the executive, middle level and senior level management in the paint manufacturing industry of Pakistan. Multiple regression, as well as Preacher and Hayes (2004) tests, were applied to test the hypotheses.

Findings - The result of the data analysis showed that IWB acts as a mediator between IOC and project success (PS), thereby supporting the hypothesized model of innovation and PS. Work culture was supported as a moderator; however, no moderating effect of gender was validated by the results.

Research limitations/implications - The management must make sure that to maximize the rate of success of projects, innovative work climate within the organizations and departments be given due importance. In addition to this, personnel's individual innovation capabilities must also be enhanced by taking steps toward improvement through training and development.
\end{abstract}

(C) Ambreen Sarwar, Muhammad Kashif Imran, Zafar-Uz-Zaman Anjum and Umer Zahid. Published in Innovation \& Management Review. Published by Emerald Publishing Limited. This article is published under the Creative Commons Attribution (CC BY 4.0) license. Anyone may reproduce, distribute, translate and create derivative works of this article (for both commercial and noncommercial purposes), subject to full attribution to the original publication and authors. The full terms of this license may be seen at http://creativecommons.org/licences/by/4.0/legalcode

Received 5 August 2019

Revised 20 February 2020

21 April 2020

9 May 2020

Accepted 11 May 2020

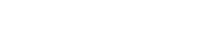


INMR

17,4

414

Originality/value - Though attention has been given to research in innovation in light of other related variables, its relation to PS remains yet to be studied. The effect of gender and work culture on innovation in Pakistani paint industry was long over-due which has been addressed by this study.

Keywords Gender, Work culture, Innovative behavior, Project success, Innovative climate, Organizational climate theory

Paper type Research paper

\section{Introduction}

For today's managers and leaders, the thorough management of innovative organizational climate (IOC) is a challenging and demanding job (Isaksen \& Ekvall, 2010). Kissi, Dainty, and Liu (2012) depicted IOC as the organization's internal innovation encouraging environment. Schneider (1990) defined it as the subjective perception of personnel regarding the environment of workplace that encourages the generation of new thoughts, concepts, methods and procedures. The foundation of innovation rests on the advancement and execution of original concepts which boosts personnel's creativity (Van de Ven, 1986).

Innovative work behavior (IWB) consists of three interrelated activities of idea initiation, promotion and realization (Janssen, 2000). Because of the affirmative results related to personnel's IWB, researchers including Janssen (2000); Kang, Matusik, Kim, and Phillips (2016); and Ren and Zhang (2015) have demonstrated increasing attention to characteristics that have the capability to boost IWB. Nonetheless, the relationship between IWB and IOC is not studied sufficiently (Shanker, Bhanugopan, Van der Heijden, \& Farrell, 2017). The strategic effect of IOC related to organizational performance $(\mathrm{OP})$ has been documented in previous research studies conducted by Naranjo-Valencia, Jiménez-Jiménez, and Sanz-Valle (2016); and Nybakk and Jenssen (2012).

Some scholars have argued that IWB can expedite the process of gaining competitive advantage and can enhance OP (Hogan \& Coote, 2014; Moss Kanter, 1988; Runco, 2004; Scott \& Bruce, 1994; Shih \& Susanto, 2011). Nonetheless, their approaches were inadequate with respect to fundamental conceptual framework (Shanker et al., 2017); and focus largely on examining the connection between IOC and OP. The present study makes a novel contribution by studying the influence of IOC and IWB on project success (PS). PS is used here as a proxy of OP because traditionally a project is thought to be successfully completed when the performance objectives, funds, budgets and deadlines are successfully fulfilled (Shenhar, Dvir, Levy, \& Maltz, 2001). Approval of the client, work quality, cost, scope and time are the issues reflected upon while evaluating PS (Guide, 2001). Additionally, moderating effect of gender and work culture on the relation between innovative climate and behavior is tested in the study.

Most existing literature pertaining to innovation was found to be conducted in developed countries such as USA (Wolf \& Pett, 2006), Canada (Branzei \& Vertinsky, 2006), England (Edwards, Delbridge, \& Munday, 2005), The Netherlands (de Jong \& Vermeulen, 2006), Turkey (Ar \& Baki, 2011) and New Zealand (Clark, 2010). Consequently, due to shortage of research studies in developing nations, the policymakers frequently use findings from developed nations when designing policy measures (Radas \& Bozic, 2009). However, the theoretical models generated with the context of developed countries in mind and their findings might not be applicable with respect to developing countries (Najib \& Kiminami, 2011).

This discussion shows that literature related to innovation in Pakistan does not provide insights into the relation between IOC, IWB and PS and this perspective is yet to be studied in the paint industry where Pakistani consumers demand more innovation (Bilal, Iqra, \& Javaid, 2010), which leads to their satisfactory experience and PS (Guide, 2001). Also, studying the effect of gender and work culture in IOC and IWB in Pakistani paint industry would be an added contribution of the study by examining empirical evidence linking 
innovation supportive climate, IWB, gender and culture and studying if the capacity for innovation among women and men; and public versus private sector differs with respect to the support they perceive for innovation from the organization. The findings from the current study would also be useful for other developing countries where work context is similar to Pakistan.

\section{Literature review}

Innovative organizational climate and project success

Organizational success depends on innovation (DiLiello \& Houghton, 2006). Climate within an organization can have a constructive influence on innovation at individual and organizational levels (Kang et al., 2016; Nybakk, Crespell, \& Hansen, 2011; Ren \& Zhang, 2015; Shanker et al., 2017). The management needs to make sure that climate within the workplace boosts employee's creativity (DiLiello \& Houghton, 2006; Haneda \& Ito, 2018). When a support from organization is perceived by the personnel, they are expected to practice innovation (DiLiello \& Houghton, 2006). Moreover, if employees perceive a facilitative workplace climate, they will be become more committed, resulting in better OP. Several studies have shown that personnel's engagement in innovation and climate for innovation result in better OP and business success (Harter, Schmidt, \& Hayes, 2002; Macey \& Schneider, 2008).

In contemporary literature, a good amount of research studied the relationship between innovation and PS (Olaisen \& Revang, 2017; Ommen, Blut, Backhaus, \& Woisetschläger, 2016). Further, Martens, Machado, Martens, and de Freitas (2018) argued that innovation helps entrepreneurs to achieve success in projects. Furthermore, IOC increases the probability of success in innovation projects (Olaisen \& Revang, 2017). Recently, Leone and Schiavone (2019) investigated the direct association between innovation and PS. However, very scant research is available in existing literature that studied the direct relationship between IOC and PS as many of the research studies only considered the relationship between innovation and PS. Based on the discussion made herein, we hypothesize that:

H1. IOC is positively associated with PS.

\section{The mediating effect of innovative work behavior}

The process of innovation is rooted in the organizational system as it not only occurs at group and organizational levels (Amabile, Conti, Coon, Lazenby, \& Herron, 1996; De Jong \& Den Hartog, 2010; Naranjo-Valencia et al., 2016; Sung \& Choi, 2014) but also at individual level. Though there is limited empirical evidence of the influence of organizational climate on employee's innovative actions at individual level, Scott and Bruce (1994) showed that supportive climate within the workplace influenced employee's IWB positively. The features of workplace climate, such as independence and choice, along with the induction of dedicated and focused knowledge seems to influence IWB (Krause, 2007). Especially when employees perceive that they are autonomous, they might sense higher levels of free-will, boosting up their innovativeness (Amabile et al., 1996; Si \& Wei, 2012). When failure is allowed and fear of presenting a strange concept is not there, creativity is stimulated. Likewise, Mikdashi (1999) proposed that to look for unique answers to complications, personnel must have the independence and liberty to break the norms.

A climate that has a purpose and provides support leads to the reduction of prospective risks which are apprehended by the innovative employees and this, in turn, boosts their work-related creativity. If the environment of the organization provides a feeling of being

\section{Role of gender and work culture}


INMR

17,4

respected and creditable to the employee then such individuals attain greater motivation for innovation directed to the attainment of preferred goals (Cohen-Meitar, Carmeli, \& Waldman, 2009). When such ideas as motivation, risk-taking, dispute, liberty and trust, which all appear to influence IWB, are combined, remarkably intersect with the factors of IOC reinforcing the anticipation that IOC is expected to have a constructed influence on IWB.

Parker, Baltes, Young, Huff, Altmann, Lacost, \& Roberts (2003) showed in their metaanalysis that the association between climate within the workplace with OP is mediated by personnel's job-related attitudes. Similarly, another meta-analysis (Harter et al., 2002) demonstrated that creating a work context that boosts and facilitates innovation in personnel can meaningfully upsurge the prospects of corporate success. Additionally, some other researchers (Crespell \& Hansen, 2009; De Silva, Howells, \& Meyer, 2018; Nybakk \& Jenssen, 2012; Shanker et al., 2017) have proposed that IOC influences OP directly and indirectly, via IWB. Such a notion is stressed by recent studies (De Jong \& Den Hartog, 2010), who highlighted the role of personnel in process of innovation as their opinions and behavior are vital for constant novelty and enhancement in accomplishing better corporate success, progress and market worth.

AS OP relies to a large degree on success of individual projects that it deals with, therefore, based on the previous discussion, it can be inferred that personnel's actions are expected to affect a project's success via efficient use of their information and technical proficiencies for commencing innovative schemes with the objective of augmenting their competitiveness. Therefore, we put forward that there is an indirect influence of IWB on the association between IOC and PS:

H2. IWB mediates the relationship between IOC and PS.

\section{The moderating effect of gender and work culture}

The role of human capital as a catalyst of innovation (put forward mainly by Moss Kanter, 1988), has gained enormous research focus (Cropley \& Cropley, 2015) and recently this interest has been diverted toward the influence and effect of women in innovation (Alsos, Ljunggren, \& Hytti, 2013; Lindberg \& Schiffbänker, 2013). Though a study carried out by Hülsheger, Anderson, and Salgado (2009) did not get support for their proposition of a negative association between innovation and diversity, some recent and more focused research studies have provided evidence of a distinguished influence of gender on innovation (Foss, Woll, \& Moilanen, 2013). Hewlett, Marshall, and Sherbin (2013) have also shown a positive impact of gender diversity on innovation. According to Foss et al. (2013, p. 299) "The gendered power aspect of business life is thus a contextual reality that is likely to affect the innovative potential of employees". Based on this discussion, we propose that:

\section{H3. Gender moderates the relationship between IOC and innovative behavior.}

There is a general agreement about differences between private and public sector employment (Rashid \& Rashid, 2012). These researchers have mentioned that, although studies have focused on the comparison between private and public sectors, they have obtained diverse results. The culture of private versus public sector organizations vary notably with respect to job contents, their quality, task interdependence, job independence, challenge, participation in decision-making, quality of social relations, variety of work and task significance (Baldwin \& Farley, 1991; as cited by Rashid \& Rashid, 2012). The literature on innovation in the public sector usually portrays a comparative dearth of 
innovation in this sector which is fundamentally less innovative as compared to the private sector (Albury, 2010).

In the past several years, studies and practice have built a progressively advanced and vigorous knowledge base related to innovation in the private sector (Hamel \& Getz, 2004). The dispersion of innovation in the public sector is as sluggish and problematical as compared to the private sector, and the conversion of services and service delivery takes longer (Albury, 2005). Several scholars have compared public and private sector innovation (Lee, Hwang, \& Choi, 2012). Bommert (2010) has linked innovation in the private sector with new product development, competitive advantage and value addition with respect to higher revenues; and innovation in the public sector with improvement in service performance and value addition with respect to public benefit.

Because private organizations confront strong international competition and fast technological transformations, adjusting to the challenging business settings has become decisive for business success (Eisenhardt \& Martin, 2000). According to Perry (2000), further empirical studies are required to embrace the larger work context for understanding organizational behavior in public-private sector organizations. Hence, in this study, we have included work-culture as a moderator between IOC and IWB by taking the public-private sector as a proxy for this work culture:

H4. Work culture moderates the relationship between IOC and innovative behavior.

\section{Research model}

\section{Methodology}

The target population of this research study was employees working in the projects department at executive, middle level and senior level management in the paint manufacturing industry. The paint industry of Pakistan was selected for this study because of the contextual relevance of this industry with the study variables. It is noted in literature that Pakistani consumers in the paint industry demand novelty and innovation in their choice of paint (Bilal, Iqra, \& Javaid, 2010), which leads to their satisfactory experience and PS (Guide, 2001). Because innovation in this industry is in high demand therefore it is relevant to study how innovation might be enhanced in this industry leading to PS and customer satisfaction.

Convenience sampling technique was used to obtain the study sample because of the geographic dispersion, cost and time constraints for conducting a survey (Jahanzeb \& Fatima, 2018). Approximately, 600 questionnaires were distributed in Pakistan. Out of these, 429 questionnaires were returned and had been found complete, resulting in a response percentage of approximately $71.5 \%$. After removing incomplete questionnaires having

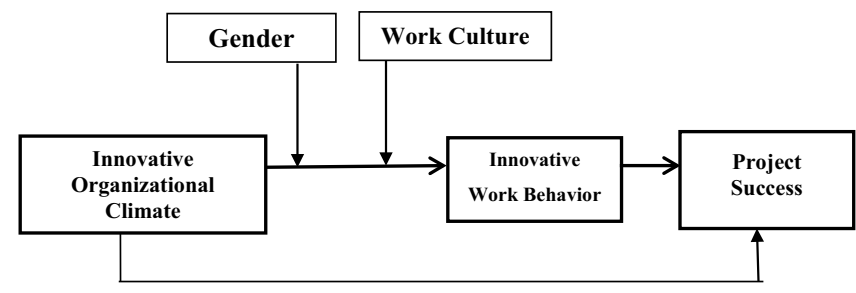

Figure 1. Research model 
INMR

17,4

\section{8}

missing responses and influential outliers, final 425 usable questionnaires were used for the analysis. Thereby, net response rate reached $70.83 \%$.

\section{Scales}

All responses were collected and measured on five-point Likert scale ranging from 1 (strongly agree) to 5 (strongly disagree) unless otherwise specified.

- IWB: For measurement of the construct of IWB the questionnaire adopted from Janssen (2000) was used in this study which consisted of nine items. The scale asked the employees how often they performed IWBs e.g. generating original solutions for problems and mobilizing support for innovative ideas.

- Innovative climate: For measurement of the construct of innovative climate, the questionnaire was adopted from Sušanj (2000) which consisted of 12 items. Example of some items are "How often are people expected to invent new ways of solving problems" and "How often is there pressure on the R\&D process because of external demand." The questionnaire though is reported by employees but contains items that portray the climate of innovation existing in the organization.

- PS: For measurement of the construct of PS, the questionnaire adopted by Harvett (2013) was used in this study. The measure consisted of six items.

\section{Data analysis}

As we aimed to investigate the indirect effect of IOC on PS through IWB, before executing the key hypotheses, various tests were conducted to check the authenticity and appropriateness of the data, i.e. data normality, reliability and correlation analysis. Further, linear regression analysis was performed to check the direct effect of IOC on IWB and PS; and Preacher and Hayes (2004) technique was applied to explore the mediating effect of IWB on relationship between IOC and PS; and the moderating effect of gender and work culture. Process macro was selected for analysis because of its ease of use, model's relevance with the study hypotheses (Hayes, 2013), and similarity in results with structural equation modeling (Hayes, Montoya, \& Rockwood, 2017).

\section{Respondent's demographic profile}

The data were obtained from employees working on various project of paint industry in Pakistan. Table 1 is reflecting the demographic statistics of the respondents. The majority of the respondents were male (i.e. $89.1 \%$ ) which is reflecting the male dominance in paint

\begin{tabular}{lllrr}
\hline Sr. no. & Description & Category & Frequency & $(\%)$ \\
\hline 1 & Gender & Male & 379 & 89.1 \\
& & Female & 46 & 10.9 \\
2 & Management level & Front level & 179 & 42.1 \\
& & Middle level & 219 & 51.6 \\
& & Senior level & 27 & 6.3 \\
3 & Age & Up to 25 & 110 & 25.4 \\
& Education & Above 25 & 315 & 74.6 \\
4 & & Graduation & 124 & 29.1 \\
& & Masters & 258 & 60.7 \\
& & M.Phil & 43 & 10.2 \\
\hline
\end{tabular}

Table 1.

Respondent's demographic profile

$$
\text { the respondents were male (i.e. } 89.1 \% \text { ) which is reflecting the male dominance in paint }
$$


industry. Further, majority of the respondents are from middle level management and having the age of above 25 years. As far as education qualification is concerned, most respondents hold master level degrees (i.e. $60.7 \%$ ).

This demographic profile also represents the general population of Pakistan where most of the workforce in masculine industries like that of paint manufacturing, is of men. As usually Pakistani students complete their graduation in early 20s therefore at middle level management, the age of more than 25 years was expected. Also, because unemployment is a reality in Pakistan (Chaudhry, 2019), it is difficult to get good job without a master's degree, which is also reflected in our sample.

\section{Normality test}

It is essential to run normality tests before executing the causal analysis as these are the prerequisite of the regression analysis. Otherwise, the results of the proposed relationship can be misleading. To check the normality of data, skewness and kurtosis test was carried out. The data was within the threshold values set by set by Hair, Black, Babin, and Anderson (2010). The skewness and kurtosis value lied between -1 and +1 . Additionally, the plot of the values graphically showed a straight line which made evident that there was no issue of normality.

Additionally, the chances of existence of heteroscedasticity were eliminated due to the standardized residuals centrality to zero with linear relationship. The variance inflation factor (VIF) and tolerance were also checked and results lied within the acceptable limits i.e. VIF 2.13 and tolerance 0.42 (Kline, 2014). With these tests regarding heteroscedasticity, VIF and tolerance, it can be inferred that the data is free from any issue of multi-collinearity. For checking the non-existence of autocorrelation, we applied Durbin-Watson test. The results demonstrated no autocorrelation. These tests and preliminary analyses permitted us to go for the regression analysis with confidence.

\section{Reliability and correlation tests}

It was ensured that all scales are reliable as Cronbach (1951) alpha's values ranged from 0.7 to 0.8, showing average to good consistency (George \& Mallery, 2016) (Table 2). Further, correlation analysis was conducted to find out the relationship among variables along with the strength of their association. The results showed that IOC has moderate positive association with IWB $(r=0.309)$ and PS $(r=0.438)$. Moreover, IWB has also moderate positive correlation with PS $(r=0.304)$. The strength of association is showing that an upward trend in IOC leads to better IWB and higher the PS.

\section{Testing the hypotheses}

Direct effects. To check the main hypotheses regarding direct effects, linear regression analysis was performed. The results revealed that all direct effect between IOC and IWB, IWB and PS and IOC and PS have significant positive effects (Table 3). The results

\begin{tabular}{lclll}
\hline Constructs & Alpha & IOC & IWB & PS \\
\hline IOC & 0.77 & 1 & & \\
IWB & 0.71 & $0.31^{* *}$ & 1 & \\
PS & 0.80 & $0.44^{*}$ & $0.31^{* *}$ & 1
\end{tabular}

Notes: ${ }^{*} \rho<0.05 ; \stackrel{* *}{\rho} \rho<0.01$

\section{Role of gender and work culture}

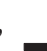


INMR

17,4

Table 3.

Regression analysis confirmed the significance of $H 1$ that IOC is positively associated with PS ( $\beta=0.35, \rho<$ 0.05). Further, substantial direct association between IOC and IWB and IWB and PS also set the basis for mediation effect of IWB between IOC and PS. Maximum variation was found between IWB and PS relationship $\left(R^{2}=0.18, t=5.42\right)$, while the lowest was between IOC and PS $\left(R^{2}=0.10, t=3.59\right)$. Moreover, the significance of these relationships sets the basis for mediation effect of IWB in relationship between IOC and PS; and moderation of gender and work culture.

Mediating effect. To check the mediating effect of IWB in relationship between IOC and PS, Preacher \& Hayes (2004) mediation test was applied with 5,000 bootstrapping. The results demonstrated that IWB has partial mediating effect on IOC-PS relationship (Table 4). A-Path revealed that there is a positive relationship between IOC and IWB with $\beta=0.31$, at $95 \%$ confidence level. Further, B-Path explained that IWB has positive relationship with PS having $\beta$ value 0.44 with significant $p$-value. $\mathrm{C}$ and $\mathrm{C}$-Path showed direct and indirect relationship between IOC and PS with mediating effect of IWB. The analysis of both paths give evidence that IWB partially mediates the relationship between IOC and PS with $\beta=$ 0.30 at significant $p$-value (C-Path) and $\beta=0.38$ at significant $p$-value (C'-Path) at $95 \%$ confidence level (Table 4). The overall statistic of $H 2$ are also significant with $R^{2}=0.23$ and $\mathrm{S} . \mathrm{E}=0.11$ that has validated the mediation effect of IWB.

For further confirmation of mediation effect, Sobel test was executed which also confirmed the mediation effect of IWB on the relationship between IOC and PS ( $Z=3.004$, $\mathrm{S} . \mathrm{E}=0.054, p=0.002$ )

Moderating effect of gender and work culture. To check the moderating effect of gender and work culture in the association between IOC and IWB, PROCESS macro developed by Hayes (2013) was used with 5,000 bootstrapping samples. H3 was not supported by our data i.e. gender does not moderate the positive relation between IOC and IWB.

\begin{tabular}{lccccc}
\hline Association & $R^{2}$ & $f$-change & $\beta$ & $t$-value & $\rho$ \\
\hline IOC $\rightarrow$ IB & 0.11 & 14.061 & 0.32 & 3.89 & ${ }^{* *}$ \\
IB $\rightarrow$ PS & 0.18 & 28.754 & 0.45 & 5.42 & $* * *$ \\
IOC $\rightarrow$ PS & 0.10 & 13.265 & 0.35 & 3.59 & 0.01
\end{tabular}

Notes: ${ }^{* * *} p<0.05 ;$ IOC $=$ Innovative organizational climate, IWB = Innovative work behavior, $\mathrm{PS}=$ project success

\begin{tabular}{lcccc}
\hline Statistical descriptions & $\begin{array}{c}\text { A-Path } \\
\text { X-M }\end{array}$ & $\begin{array}{c}\text { B-Path } \\
\text { M-Y }\end{array}$ & $\begin{array}{c}\text { C-Path } \\
\text { X-Y }\end{array}$ & C'-Path $^{1}$ X(M)-Y \\
\hline Un-standardized Beta & 0.31 & 0.44 & 0.30 & 0.380 \\
$P$-value & 0.000 & 0.000 & 0.001 & 0.000 \\
$F$-change & 13.021 & 29.14 & 12.581 & 17.477 \\
$R^{2}$ & & & 0.23 & \\
Adjusted $R^{2}$ & & & 0.22 & \\
Significance value & & 0.000 & \\
S.E & & 0.11 &
\end{tabular}

Table 4.

Mediation test (IOC, IWB, PS) 
The interaction term was found to be non-significant (Table 5). Because the confidence interval included zero in the interval and was not significantly different from zero (coefficient $=0.01, \mathrm{~S} . \mathrm{E}=0.039, p=0.199, \mathrm{CI}=-0.21$ to 0.054 ), therefore the hypothesis H5 has been rejected. However, $H 4$ of the study was fully supported, as the data analysis provided evidence of a significant moderation of work culture. The interaction term was found to be significant (Table 5). Because the confidence interval did not include zero in the interval and was significantly different from zero (Coefficient $=0.08, \mathrm{~S} . \mathrm{E}=0.041, p<0.001$, $\mathrm{CI}=-0.13$ to -0.037 ), so the hypothesis $H 6$ has been accepted i.e. the positive association between IOC and IWB was found to be stronger in the private sector (private: $0.54, p<$ 0.001; public: $0.22, p<0.001$; Table 6 ) as compared to the public sector (Figure 2).

After getting the results from process macro, which demonstrated no moderation effect of gender and a significant moderation of work culture between IOC and IWB, the critical values and path coefficients were calculated to check the moderating role of these two sets on the aforementioned association. The values of Table 7 show that women are no different to men employees with respect to innovative behavior due to IOC. Additionally, individual's innovative behavior because of the innovative work climate is more widespread in the private sector in comparison to the private sector.

\section{Discussion}

One important conclusion of this research is that personnel who show IWB furthers the likelihoods of PS. This finding is like the findings of Woodman, Sawyer, and Griffin (1993) and Amabile (1988), who have put forward that personal readiness is vital for innovative firms, which guides to sustainable success of the organization (Shih \& Susanto, 2011; Tushman \& O'Reilly, 1996). The results are also similar to the findings of other authors

\begin{tabular}{llcccr}
\hline & $\beta$ & S.E. & $95 \%$ CI & $R^{2}$ & $\Delta R^{2}$ \\
\hline Constant & 0.79 & 0.363 & $-0.079 ; 1.50$ & & \\
Gender (G; moderator) & 0.15 & 0.101 & $-0.042 ; 0.355$ & & \\
IOC (IV) & $0.94^{*}$ & 0.135 & $0.679 ; 1.21$ & & \\
Interaction (G $\times$ IOC) & 0.01 & 0.039 & $-0.210 ; 0.054$ & 0.14 & 0.002 \\
Model 1 $R^{2}$ & & & & & \\
Constant & $0.51^{*}$ & 0.027 & $0.008 ; 0.097$ & & \\
WC (moderator) & $0.20^{*}$ & 0.022 & $-0.24 ;-0.156$ & & $0.009^{*}$ \\
Interaction (WC $\times$ IOC) & $0.08^{*}$ & 0.024 & $-0.131 ;-0.037$ & $0.26^{*}$ & \\
Model 2 $R^{2}$ & & & & &
\end{tabular}

Role of gender and work culture

\section{$-$}




\section{INMR}

17,4

Figure 2.

Moderation of work culture

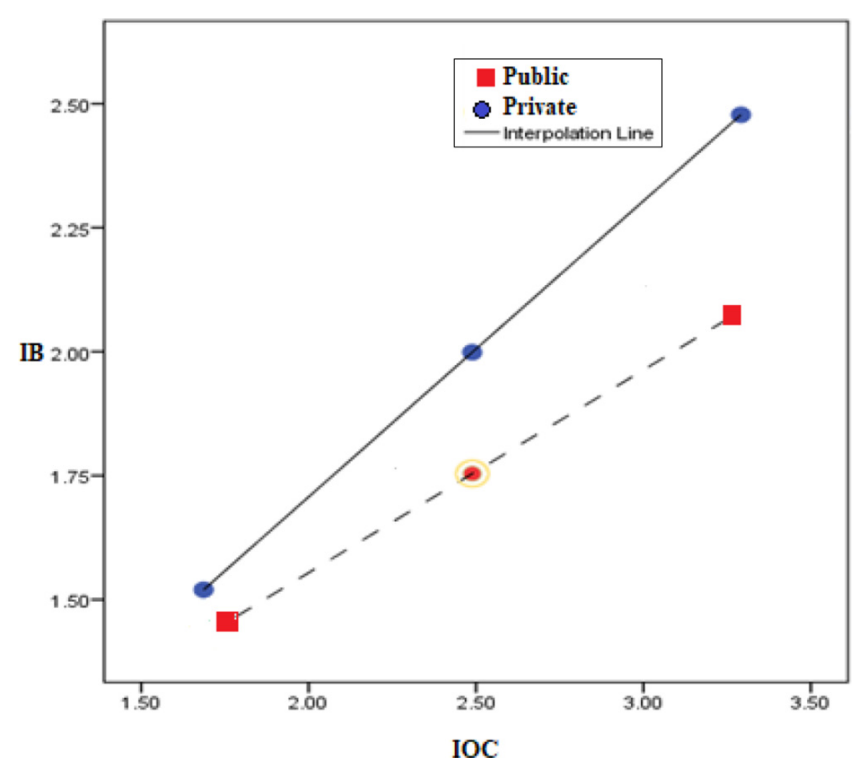

(Amabile, 1997; George \& Zhou, 2001; Oldham \& Cummings, 1996; Runco, 2004; Scott \& Bruce, 1994; Yuan \& Woodman, 2010), who have shown that IWB is important in capturing competitive edge.

The results of our study are also in line with some recent studies carried out in various cultural contexts. For instance, the study of Shanker et al. (2017), who showed a link between IOC, IWB and OP in the Malaysian context. Additionally, Vincent, Bharadwaj, and Challagalla (2004) claimed that there is positive relationship between innovation and better performance of personnel and that it significantly boosts the performance of an organization. For attaining a better personal and OP, it is imperative that the behaviors be directed to the execution and improvement of ideas, in addition to idea generation (De Jong \& Den Hartog, 2010). The results of current study would also benefit other developing nations, as studies related to innovation in such countries are scarce.

We also expand the efforts of Parker et al. (2003), who demonstrated the association of IOC and OP to be mediated by work-related attitudes of personnel. Finally, as stated before, earlier research studies have shown mixed findings related to the influence of gender (Cropley \& Cropley, 2015; Hülsheger et al., 2009; Foss et al., 2013; Hewlett, Marshall, \& Sherbin, 2013) and work-culture (Albury, 2010; Hamel \& Getz, 2004; Lee, Hwang \& Choi, 2012; Foss et al., 2013), in relation to innovation. Our findings have demonstrated that, in the Pakistani paint industry, gender does not play any role, whereas work-culture does. Women 
in this industry are no different than men in IWB arising from innovative organizational culture, however, differences prevail with respect to the said relationship between the public and private sectors where IOC affects the employees IB more in the private sector, as compared to the public sector.

The existing literature about some sectors of developed economies show that, though they are usually considered as the cradles of economic strength and innovation, they continue to be dominated by men (Cropley \& Cropley, 2017). This seems to suggest that innovation is men's business (Cropley, 2002). However, our results have shown that if

Role of gender and work culture women are provided with the supportive innovation climate, they are not inferior to men in displaying IWB, if not better. Moreover, the reason behind the prevalence of innovative behavior in private sector as compared to the public sector might be the job security offered by the public sector jobs in Pakistan (Saidan, 2019). As it is not easy to lose a public sector job under normal conditions, the employees here might be less inclined to spend their energies in innovation and not even the innovation supportive climate provided by the organization would affect their innovative abilities much as compared to the private sector.

\section{Theoretical implications}

This study contributes to the literature significantly by deepening the comprehension of personnel's IWB and PS. Drawing on the organizational climate theory, within the domain of industrial and organizational psychology, our study puts forward that IOC plays a significant role in effecting personnel's IWB which contributes toward the success of project. The results of this research are in line with researchers like Yeoh and Mahmood (2013), who demonstrated a positive link between IOC and personnel's IWB, yet they overlooked the analysis between interaction and PS.

Additionally, we contribute to the extant literature of organizational climate (Kang et al., 2016; Kuenzi \& Schminke, 2009; Nybakk \& Jenssen, 2012; Patterson, Warr, \& West, 2004; Ren \& Zhang, 2015; Senge, 1991) by showing that the management and leadership having the skills and ability to properly manage the climate aspects of workplace such as ideation leadership and support; would have better chances of stimulating innovation among employees. Odoardi, Battistelli, and Montani (2010) have put forward that feeling of support and encouragement in terms of generating, practicing and improving novel innovative ideas might give a boost to personnel's efficacy for initiating and sustaining IWB. For this it is also vital to concentrate on the IOC aspects.

\section{Implications for practice}

The results of this study offer various practical implications for PS. The leadership should contemplate to stimulate creativity and innovation in their employees and organization. Employee's behavior at work is influenced by the level of support they sense from management and workplace climate (Eisenbeiss, van Knippenberg, \& Boerner, 2008). It is important for the employees to feel safe among work group members at job to avoid any reluctance in terms of idea generation, articulation and sharing (Shanker et al., 2017). Human resource (HR) and project managers, must understand the importance of aligning HR policies with goals of improving innovative climate which can encourage individual's innovative behavior e.g. fresh structures, policies, procedures, autonomy, reward and recognition programs. Organizations should train project managers to be supportive toward new ideas. Particularly, this study has provided a vital steppingstone to Pakistani project managers for nurturing a workplace innovative climate and behavior which can augment the rate of their PS. Due to the social, economic and environmental pressures, private organizations are required to innovate and try novel practices and paths of nurturing 
INMR

17,4

innovation to counteract stagnation (Foss et al., 2013) as compared to the public sector organizations. This means that the influence of organizational structures and work environment (Amabile et al., 1996) on innovation is more pertinent than ever before.

The gender asymmetry found in industries such as the paint industry have several consequences regarding innovation. First, some male-dominated organizations might be under-performing in innovation but would be ignorant about it because they benchmark against equally asymmetric organizations. Second, a vicious cycle of gender-induced underperformance regarding innovation might be created because of the male-dominated environment and organizational culture that actively drive women away from these organizations. Third, the strong prevailing stereotypes about "typical female" are the opposite of the psychological prerequisites for innovative behavior (Cropley \& Cropley, 2015). When such stereotypes are instilled in women's minds, they might not only drive them away, but would also hamper the innovation capacity of the ones who stay, and subsequently of the entire organization. Such discussion though might purely mirror and strengthen the gendered nature of innovation research (Robb \& Coleman, 2014), however, our study has shown that a handful of women working in the Pakistani paint industry are not influenced by the male domination and innovate in similar capacities when provided with supportive environment for innovation.

\section{Study limitations and recommendations}

Despite the contributions showed herein, our study presents some limitations. First, the cross-sectional nature of the study does not permit to make causal conclusions. For addressing this, future researchers need to focus on longitudinal or experimental designs. Second, the data was collected from paint manufacturing companies operating in Pakistan, therefore generalizations should be cautiously made. Therefore, the study might be replicated in other regions, sectors and industries. Moreover, the current research has studied the direct association between IOC and IWB. It is quite possible that this relationship might be more multifaceted and moderated by other variables. Therefore, it would be logical to include other mediators, such as job engagement or motivation (Amabile et al., 1996; Carmeli \& Spreitzer, 2009; Yuan \& Woodman, 2010).

Additionally, our study has offered country-neutral arguments while developing the hypotheses, but some factors such as cultural settings might interfere with the generalizability of our study model. For instance, the study context (Pakistan) of this research is characterized by high uncertainty avoidance (De Clercq, Haq, \& Azeem, 2017), due to which employees might be principally sensitive to events that create uncertainty in their lives (Hofstede, 2001), such as innovation. Also, Pakistan is marked by collectivism (Hofstede, 1991; Jahanzeb \& Fatima, 2018) as manifested through key roles played by family and kinship structures; and power distance (Jahanzeb, Fatima, Bouckenooghe, \& Bashir, 2019). Earlier it has been shown that uncertainty avoidance (Shane, 1993; Swierczek \& Ha, 2003; Shane, 1995) is related to lower innovation rates, however, collectivism and power distance (Shane, 1993) are related to higher rates of innovation. This suggests that further cross-national studies might provide deeper insights into the studied variables. Additionally, replicating our model for studying the moderating role of cultural characteristics might also be fruitful to better comprehend the phenomenon under study.

The theoretical framework of this study also aids in identifying IWB as a positive predictor of PS. Our findings, in line with several other studies (Shanker et al., 2017; Shih \& Susanto, 2011) has shown IWB to influence OP positively and therefore result in attainment of competitive edge. It is possible that the association between the two variables might be 
more complex in nature, as the relationship might be direct or indirect with the presence of other potential mediators which may affect the chances of PS.

\section{Conclusion}

The present research contributed to literature by studying the direct and indirect relationship between IOC and PS through IWB; as well as the moderating role of gender and work culture between IOC and IWB. The hypothesized model was tested through SPSS. The results showed a significant association between IOC and PS; and that IOC had a significant and positive effect on IWB. This shows that the presence of innovation in supportive climate plays significant role in improving IWB. Additionally, the study also provided support for the fact that individuals in private sector are more affected by IOC with respect to IWB as compared to public sector employees. However, no such difference was found between male and female employees.

\section{References}

Alsos, G. A., Ljunggren, E., \& Hytti, U. (2013). Gender and innovation: state of the art and a research agenda. International Journal of Gender and Entrepreneurship, 5(3), 236-256. doi: https://doi.org/ 10.1108/IJGE-06-2013-0049.

Amabile, T. M. (1988). A model of creativity and innovation in organizations. Research in Organizational Behavior, 36(1), 123-167. doi: https://doi.org/10.1016/j.riob.2016.10.001.

Amabile, T. M. (1997). Motivating creativity in organizations: on doing what you love and loving what you do. California Management Review, 40(1), 39-58. doi: https://doi.org/10.2307/41165921.

Amabile, T. M., Conti, R., Coon, H., Lazenby, J., \& Herron, M. (1996). Assessing the work environment for creativity. Academy of Management Journal, 39(5), 1154-1184. doi: https://doi.org/10.2307/ 256995

Ar, I. M., \& Baki, B. (2011). Antecedents and performance impacts of product versus process innovation: empirical evidence from SMEs located in Turkish science and technology parks. European Journal of Innovation Management, 14(2), 172-206. doi: https://doi.org/10.1108/ 14601061111124885.

Bilal, A., Iqra, I., \& Javaid, J. (2010). Mass customization and customer's satisfaction in paint industry of Pakistan. NUML Journal of Management \& Technology, 28.

Branzei, O., \& Vertinsky, I. (2006). Strategic pathways to product innovation capabilities in SMEs. Journal of Business Venturing, 21(1), 75-105. doi: https://doi.org/10.1016/j.jbusvent.2004.10.002.

Carmeli, A., \& Spreitzer, G. M. (2009). Trust, connectivity, and thriving: implications for innovative behaviors at work. The Journal of Creative Behavior, 43(3), 169-191. doi: https://doi.org/10.1002/ j.2162-6057.2009.tb01313.x.

Chaudhry, S. (2019). Unemployment in Pakistan: reason behind this persistent issue. Retrieved 20th December 2019. Retrieved from: http://blogs.dunyanews.tv/24993/

Clark, D. N. (2010). Innovation management in SMEs: active innovators in New Zealand. Journal of Small Business \& Entrepreneurship, 23(4), 601-619. doi: https://doi.org/10.1080/ 08276331.2010.10593504.

Cohen-Meitar, R., Carmeli, A., \& Waldman, D. A. (2009). Linking meaningfulness in the workplace to employee creativity: the intervening role of organizational identification and positive psychological experiences. Creativity Research Journal, 21(4), 361-375. doi: https://doi.org/ 10.1080/10400410902969910.

Crespell, P., \& Hansen, E. (2009). Antecedents to innovativeness in the forest products industry. Journal of Forest Products Business Research, 6(1), 1-20.

\section{Role of gender and work culture}


INMR

17,4

Cronbach, L. J. (1951). Coefficient alpha and the internal structure of tests. Psychometrika, 16(3), 297-334. doi: https://doi.org/10.1007/BF02310555.

Cropley, A. J. (2002). Creativity and innovation: men's business or women's work?, Baltic Journal of Psychology, 3, 77-88.

Cropley, D. H., \& Cropley, A. J. (2015). The psychology of innovation in organizations, New York, NY: Cambridge University Press.

Cropley, D., \& Cropley, A. (2017). Innovation capacity, organisational culture and gender. European Journal of Innovation Management, 20(3) doi: https://doi.org/10.1108/EJIM-12-2016-0120.

De Clercq, D., Haq, I. U., \& Azeem, M. U. (2017). Perceived threats of terrorism and job performance: the roles of job-related anxiety and religiousness. Journal of Business Research, 78, 23-32. doi: https://doi.org/10.1016/j.jbusres.2017.04.013.

De Jong, J., \& Den Hartog, D. (2010). Measuring innovative work behaviour. Creativity and Innovation Management, 19(1), 23-36. doi: https://doi.org/10.1111/j.1467-8691.2010.00547.x.

de Jong, J. P. J., \& Vermeulen, P. A. M. (2006). Determinants of product innovation in small firms. International Small Business Journal: Researching Entrepreneurship, 24(6), 587-609. doi: https:// doi.org/10.1177/0266242606069268.

De Silva, M., Howells, J., \& Meyer, M. (2018). Innovation intermediaries and collaboration: knowledgebased practices and internal value creation. Research Policy, 47(1), 70-87. doi: https://doi.org/ 10.1016/j.respol.2017.09.011.

DiLiello, T. C., \& Houghton, J. D. (2006). Maximizing organizational leadership capacity for the future: toward a model of self-leadership, innovation and creativity. Journal of Managerial Psychology, 21(4), 319-337. doi: https://doi.org/10.1108/02683940610663114.

Edwards, T., Delbridge, R., \& Munday, M. (2005). Understanding innovation in small and mediumsized enterprises: a process manifest. Technovation, 25(10), 1119-1127. doi: https://doi.org/ 10.1016/j.technovation.2004.04.005.

Eisenbeiss, S. A., van Knippenberg, D., \& Boerner, S. (2008). Transformational leadership and team innovation: integrating team climate principles. Journal of Applied Psychology, 93(6), 1438 doi: https://doi.org/10.1037/a0012716.

Fatima, T. (2017). Interactive effects of workplace ostracism and belief in reciprocity on fear of negative evaluation. Pakistan Journal of Commerce and Social Sciences (PJCSS), 11(3), 911-933.

Foss, L., Woll, K., \& Moilanen, M. (2013). Creativity and implementations of new ideas: do organisational structure, work environment and gender matter?, International Journal of Gender and Entrepreneurship, 5(3), 298-322. doi: https://doi.org/10.1108/IJGE-09-2012-0049.

George, D., \& Mallery, P. (2016). IBM SPSS statistics 23 step by step: a simple guide and reference, London: Routledge.

George, J. M., \& Zhou, J. (2001). When openness to experience and conscientiousness are related to creative behavior: an interactional approach. Journal of Applied Psychology, 86(3), 513 doi: https://doi.org/10.1037/0021-9010.86.3.513.

Guide, A. (2001). Project management body of knowledge PMBOK® GUIDE, In Project Management Institute.

Hair, J. F., Black, WC, Babin, BJ, \& Anderson, RE (2010). Multivariate data analysis, 7.

Haneda, S., \& Ito, K. (2018). Organizational and human resource management and innovation: which management practices are linked to product and/or process innovation?. Research Policy, 47(1), 194-208. doi: https://doi.org/10.1016/j.respol.2017.10.008.

Harter, J. K., Schmidt, F. L., \& Hayes, T. L. (2002). Business-unit-level relationship between employee satisfaction, employee engagement, and business outcomes: a meta-analysis. Journal of Applied Psychology, 87(2), 268 doi: https://doi.org/10.1037/0021-9010.87.2.268. 
Harvett, C. M. (2013). A study of uncertainty and risk management practice related to perceived project complexity.

Hayes, A. F. (2013). The PROCESS macro for SPSS and SAS (version 2.13) [software].

Hayes, A. F., Montoya, A. K., \& Rockwood, N. J. (2017). The analysis of mechanisms and their contingencies: PROCESS versus structural equation modeling. Australasian Marketing Journal (AMJ), 25(1), 76-81. doi: https://doi.org/10.1016/j.ausmj.2017.02.001.

Hewlett, S. A., Marshall, M., \& Sherbin, L. (2013). How diversity can drive innovation. Harvard Business Review, 91(12), 30.

Hofstede, G. (1991). Culture and organizations (intercultural communication and its importance for survival). In J. L. Hofstede, (Ed.) Software of the Mind, New York, NY: McGraw Hill.

Hofstede, G. (2001). Culture's consequences: Comparing values, behaviors, institutions and organizations across nations, New York, NY: Sage publications.

Hogan, S. J., \& Coote, L. V. (2014). Organizational culture, innovation, and performance: a test of Schein's model. Journal of Business Research, 67(8), 1609-1621. doi: https://doi.org/10.1016/j. jbusres.2013.09.007.

Hülsheger, U. R., Anderson, N., \& Salgado, J. F. (2009). Team-level predictors of innovation at work: a comprehensive Meta-analysis spanning three decades of research. Journal of Applied Psychology, 94(5), 1128-1145. doi: https://doi.org/10.1037/a0015978.

Isaksen, S. G., \& Ekvall, G. (2010). Managing for innovation: the two faces of tension in creative climates. Creativity and Innovation Management, 19(2), 73-88. doi: https://doi.org/10.1111/ j.1467-8691.2010.00558.x.

Jahanzeb, S., \& Fatima, T. (2018). How workplace ostracism influences interpersonal deviance: the mediating role of defensive silence and emotional exhaustion. Journal of Business and Psychology, 33(6), 779-791. doi: https://doi.org/10.1007/s10869-017-9525-6.

Jahanzeb, S., Fatima, T., Bouckenooghe, D., \& Bashir, F. (2019). The knowledge hiding link: a moderated mediation model of how abusive supervision affects employee creativity. European Journal of Work and Organizational Psychology, 28(6), 810-819. doi: https://doi.org/10.1080/ 1359432X.2019.1659245.

Janssen, O. (2000). Job demands, perceptions of effort-reward fairness and innovative work behaviour. Journal of Occupational and Organizational Psychology, 73(3), 287-302. doi: https://doi.org/ 10.1348/096317900167038.

Kang, J. H., Matusik, J. G., Kim, T.-Y., \& Phillips, J. M. (2016). Interactive effects of multiple organizational climates on employee innovative behavior in entrepreneurial firms: a cross-level investigation. Journal of Business Venturing, 31(6), 628-642. doi: https://doi.org/10.1016/j. jbusvent.2016.08.002.

Kissi, J., Dainty, A., \& Liu, A. (2012). Examining Middle managers' influence on innovation in construction professional services firms: a tale of three innovations. Construction Innovation, 12(1), 11-28. doi: https://doi.org/10.1108/14714171211197472.

Kline, P. (2014). An easy guide to factor analysis, London: Routledge.

Krause, T. (2007). The effective safety leader: personality, values and emotional commitment. Occupational Hazards, 69(9), 24.

Kuenzi, M., \& Schminke, M. (2009). Assembling fragments into a lens: a review, critique, and proposed research agenda for the organizational work climate literature. Journal of Management, 35(3), 634-717. doi: https://doi.org/10.1177/0149206308330559.

Leone, D., \& Schiavone, F. (2019). Innovation and knowledge sharing in crowd funding: how social dynamics affect project success. Technology Analysis \& Strategic Management, 31(7), 803-816.

Lindberg, M., \& Schiffbänker, H. (2013). Gender and innovation. In E. G. Carayannis, (Ed.), Encyclopedia of creativity, invention, innovation and entrepreneurship, pp. 782-789. New York, NY: Springer.

Role of gender and work culture

\section{$\sqrt{10}$}


INMR

17,4
Macey, W. H., \& Schneider, B. (2008). The meaning of employee engagement. Industrial and Organizational Psychology, 1(1), 3-30. doi: https://doi.org/10.1111/j.1754-9434.2007.0002.x.

Martens, C. D. P., Machado, F. J., Martens, M. L., \& de Freitas, H. M. R. (2018). Linking entrepreneurial orientation to project success. International Journal of Project Management, 36(2), 255-266. doi: https://doi.org/10.1016/j.ijproman.2017.10.005.

Mikdashi, T. (1999). Constitutive meaning and aspects of work environment affecting creativity in Lebanon. Participation and Empowerment: An International Journal, 7(3), 47-55. doi: https://doi. org/10.1108/14634449910277793.

Moss Kanter, R. (1988). When a thousand flowers bloom: structural, collective and social conditions for innovation in organization. In B. M. Staw, \& L. L. Cummings, (Eds), Research in organizational behavior, Amsterdam: Elsevier, p. 10.

Najib, M., \& Kiminami, A. (2011). Innovation, cooperation and business performance some evidence from Indonesian small food processing cluster. Journal of Agribusiness in Developing and Emerging Economies, 1(1), 75-96. doi: https://doi.org/10.1108/20440831111131523.

Naranjo-Valencia, J. C., Jiménez-Jiménez, D., \& Sanz-Valle, R. (2016). Studying the links between organizational culture, innovation, and performance in Spanish companies. Revista Latinoamericana de Psicología, 48(1), 30-41. doi: https://doi.org/10.1016/j.rlp.2015.09.009.

Nybakk, E., \& Jenssen, J. I. (2012). Innovation strategy, working climate, and financial performance in traditional manufacturing firms: an empirical analysis. International Journal of Innovation Management, 16(02), doi: https://doi.org/10.1142/S1363919611003374.

Nybakk, E., Crespell, P., \& Hansen, E. (2011). Climate for innovation and innovation strategy as drivers for success in the wood industry: moderation effects of firm size, industry sector, and country of operation. Silva Fennica, 45(3), 415-430. doi: https://doi.org/10.14214/sf.110.

Odoardi, C. Battistelli, A., \& Montani, F. (2010). Can goal theories explain innovative work behaviour? The motivating power of innovation-related goals. BPA-Applied Psychology Bulletin (Bollettino Di Psicologia Applicata).

Olaisen, J., \& Revang, O. (2017). The dynamics of intellectual property rights for trust, knowledge sharing and innovation in project teams. International Journal of Information Management, 37(6), 583-589. doi: https://doi.org/10.1016/j.ijinfomgt.2017.05.012.

Oldham, G. R., \& Cummings, A. (1996). Employee creativity: personal and contextual factors at work. Academy of Management Journal, 39(3), 607-634. doi: https://doi.org/10.5465/256657.

Ommen, N. O., Blut, M., Backhaus, C., \& Woisetschläger, D. M. (2016). Toward a better understanding of stakeholder participation in the service innovation process: more than one path to success. Journal of Business Research, 69(7), 2409-2416. doi: https://doi.org/10.1016/j. jbusres.2016.01.010.

Parker, C. P., Baltes, B. B., Young, S. A., Huff, J. W., Altmann, R. A., Lacost, H. A., \& Roberts, J. E. (2003). Relationships between psychological climate perceptions and work outcomes: a meta-analytic review. Journal of Organizational Behavior, 24(4), 389-416. doi: https://doi.org/10.1002/job.198.

Patterson, M., Warr, P., \& West, M. (2004). Organizational climate and company productivity: the role of employee affect and employee level. Journal of Occupational and Organizational Psychology, 77(2), 193-216. doi: https://doi.org/10.1348/096317904774202144.

Perry, J. L. (2000). Bringing society in: toward a theory of public-service motivation. Journal of Public Administration Research and Theory, 10(2), 471-488. doi: https://doi.org/10.1093/oxfordjournals. jpart.a024277.

Preacher, K. J., \& Hayes, A. F. (2004). SPSS and SAS procedures for estimating indirect effects in simple mediation models. Behavior Research Methods, Instruments, \& Computers, 36(4), 717-731. doi: https://doi.org/10.3758/BF03206553.

Radas, S., \& Bozic, L. (2009). The antecedents of SME innovativeness in an emerging transition economy. Technovation, 29(6-7), 438-450. doi: https://doi.org/10.1016/j.technovation.2008.12.002. 
Rashid, S., \& Rashid, U. (2012). Work motivating differences between public and private sector. American International Journal of Social Science, 1(2), 24-33. Retrieved from: www.aijssnet. com/journals/Vol_1_No_2_December_2012/3.pdf

Ren, F., \& Zhang, J. (2015). Job stressors, organizational innovation climate, and employees' innovative behavior. Creativity Research Journal, 27(1), 16-23. doi: https://doi.org/10.1080/ 10400419.2015.992659.

Runco, M. A. (2004). Annual Review of Psychology, 55(1), 657-687. Retrieved from: https://doi.org/10.1146/ annurev.psych.55.090902.141502.

Role of gender and work culture

Saidan, N. (2019). Government jobs vs private jobs: what is best in Pakistan? Retrieved from: https:// career.jobs.com.pk/government-jobs-vs-private-jobs-what-is-best-in-pakistan/ (accessed 2 January, 2020).

Schneider, B. (1990). Organizational climate and culture, Ablar: Pfeiffer.

Scott, S. G., \& Bruce, R. A. (1994). Determinants of innovative behavior: a path model of individual innovation in the workplace. Academy of Management Journal, 37(3), 580-607.

Shane, S. (1993). Cultural influences on national rates of innovation. Journal of Business Venturing, 8(1), 59-73. doi: https://doi.org/10.1016/0883-9026(93)90011-S.

Shane, S. (1995). Uncertainty avoidance and the preference for innovation championing roles. Journal of International Business Studies, 26(1), 47-68. doi: https://doi.org/10.1057/palgrave.jibs.8490165.

Senge, P. M. (1991). The fifth discipline, the art and practice of the learning organization. Performance + Instruction, 30(5), 37 doi: https://doi.org/10.1002/pfi.4170300510.

Shanker, R., Bhanugopan, R., Van der Heijden, B. I. J. M., \& Farrell, M. (2017). Organizational climate for innovation and organizational performance: the mediating effect of innovative work behavior. Journal of Vocational Behavior, 100, 67-77. doi: https://doi.org/10.1016/j. jvb.2017.02.004.

Shenhar, A. J., Dvir, D., Levy, O., \& Maltz, A. C. (2001). Project success: a multidimensional strategic concept. Long Range Planning, 34(6), 699-725. doi: https://doi.org/10.1016/S00246301(01)00097-8.

Shih, H.-A., \& Susanto, E. (2011). Is innovative behavior really good for the firm? Innovative work behavior, conflict with coworkers and turnover intention: moderating roles of perceived distributive fairness. International Journal of Conflict Management, 22(2), 111-130. doi: https:// doi.org/10.1108/10444061111126666.

Si, S., \& Wei, F. (2012). Transformational and transactional leaderships, empowerment climate, and innovation performance: a multilevel analysis in the Chinese context. European Journal of Work and Organizational Psychology, 21(2), 299-320. doi: https://doi.org/10.1080/ 1359432X.2011.570445.

Sung, S. Y., \& Choi, J. N. (2014). Do organizations spend wisely on employees? Effects of training and development investments on learning and innovation in organizations. Journal of Organizational Behavior, 35(3), 393-412. doi: https://doi.org/10.1002/job.1897.

Sušanj, Z. (2000). Innovative climate and culture in manufacturing organizations: differences between some European countries. Social Science Information, 39(2), 349-361. doi: https://doi.org/ 10.1177/053901800039002011.

Swierczek, F. W., \& Ha, T. T. (2003). Entrepreneurial orientation, uncertainty avoidance and firm performance: an analysis of Thai and Vietnamese SMEs. The International Journal of Entrepreneurship and Innovation, 4(1), 46-58. doi: https://doi.org/10.5367/000000003101299393.

Tushman, M. L., \& O'Reilly, C. A. III, (1996). Ambidextrous organizations: managing evolutionary and revolutionary change. California Management Review, 38(4), 8-29. doi: https://doi.org/10.2307/ 41165852.

Van de Ven, A. H. (1986). Central problems in the management of innovation. Management Science, 32(5), 590-607. doi: https://doi.org/10.1287/mnsc.32.5.590. 
INMR

17,4

Vincent, L. H. Bharadwaj, S. G., \& Challagalla, G. N. (2004). Does innovation mediate firm performance? A meta-analysis of determinants and consequences of organizational innovation.

Wolf, J. A., \& Pett, T. L. (2006). Small-firm performance: modeling the role of product and process improvements. Journal of Small Business Management, 44(2), 268-284. doi: https://doi.org/ 10.1111/j.1540-627X.2006.00167.x.

Woodman, R. W., Sawyer, J. E., \& Griffin, R. W. (1993). Toward a theory of organizational creativity. The Academy of Management Review, 18(2), 293-321. doi: https://doi.org/10.2307/258761.

Yeoh, K. K., \& Mahmood, R. (2013). The relationship between pro-innovation organizational climate, leader-member exchange and innovative work behavior: a study among the knowledge workers of the knowledge intensive business services in Malaysia. Business Management Dynamics, 2(8), $15-30$.

Yuan, F., \& Woodman, R. W. (2010). Innovative behavior in the workplace: the role of performance and image outcome expectations. Academy of Management Journal, 53(2), 323-342. doi: https://doi. org/10.5465/amj.2010.49388995.

\section{Further reading}

Mansoor, Z. (2011). Football industry hub Sialkot struggles forward. Retrieved from http:// dinarstandard.com/challenges/football-industry-hub-sialkot-struggles-forward-2/ (accessed 11 February 2013).

Tanveer, M. A., Rizvi, S., \& Riaz, W. (2012). Declining market share of Pakistan in football industry. Asian Journal of Business and Management Sciences, 1(11), 33-42.

\section{Corresponding author}

Ambreen Sarwar can be contacted at: ambreen_sarwar@hotmail.com

For instructions on how to order reprints of this article, please visit our website: 